\title{
SUSTAINABLE DEVELOPMENT, PLANNING AND POVERTY ALLEVIATION
}

\author{
Jean-Claude BOLAY, CODEV EPFL, Switzerland \\ Eléonore LABATTUT, CODEV EPFL, Switzerland
}

\section{Abstract}

In 2018, the world population is around 7.6 billion, 4.2 billion in urban settlements and 3.4 billion in rural areas. Of this total, according to UN-Habitat, 3.2 billion of urban inhabitants live in southern countries. Of them, one billion, or nearly a third, live in slums. Urban poverty is therefore an endemic problem that has not been solved despite all initiatives taken to date by public and private sectors.

This global transformation of our contemporary societies is particularly challenging in Asia and Africa, knowing that on these two continents, less than half of the population currently lives in urban areas. In addition, over the next decades, $90 \%$ of the urbanization process will take place in these major regions of the world. Urban planning is not an end in itself. It is a way, human and technological, to foresee the future and to act in a consistent and responsible way in order to guarantee the wellbeing of the populations residing in cities or in their peripheries.

Many writers and urban actors in the South have criticized the inadequacy of urban planning to the problems faced by the cities confronting spatial and demographic growth. For many of them the reproduction of Western models of planning is ineffective when the urban context responds to very different logics. It is therefore a question of reinventing urban planning on different bases. And in order to address the real problems that urban inhabitants and authorities are facing, and offering infrastructures and access to services for all, this with the prospect of reducing poverty, to develop a more inclusive city, with a more efficient organization, in order to make it sustainable, both environmental than social and economic.

The field work carried out during recent years in small and medium-sized cities in Burkina Faso, Brazil, Argentina and Vietnam allows us to focus the attention of specialists and decision makers on intermediate cities that have been little studied but which are home to half of the world's urban population.

From local diagnoses, we come to a first conclusion. Many small and medium-sized cities in the South can be considered as poor cities, from four criteria. They have a relatively large percentage of the population is considered to be poor; the local government and its administration do not have enough money to invest in solving the problems they face; these same authorities lack the human resources to initiate and manage an efficient planning process; urban governance remains little open to democratic participation and poorly integrates social demand into its development plans. Based on this analysis, we consider it is imperative to renovate urban planning as part of a more participatory process that meets the expectations of citizens with more realistic criteria.

This process incorporates different stages: an analysis grounded on the identification of urban investment needed to improve the city; the consideration of the social demands; a realistic assessment of the financial resources to be mobilized (municipal budget, taxes, public and international external grants, public private partnership); a 
continuous dialogue between urban actors to determine the urban priorities to be addressed in the coming years.

This protocol serves as a basis for comparative studies between cities in the South and a training program initiated in Argentina for urban actors in small and mediumsized cities, which we wish to extend later to other countries of the South

\section{Keywords}

Urban planning, sustainable development, poverty, global South, intermediate cities

\section{Urban complexity: Growing cities in developing countries, growing issues?}

The Global South is currently experiencing strong urbanization, particularly demographically and territorially. In parallel, cultural references are changing in terms of lifestyles and the social and economic integration of a growing urban population. In 2018, the world population reached nearly 7.6 billion, 4.2 billion of which lived in urban areas and 3.4 billion in rural ones. According to UN-Habitat, 3.2 billion urban inhabitants live in South countries. Of these, one billion - or nearly a third - live in slums. Urban poverty is therefore an endemic problem that has not yet been solved, despite the many initiatives taken by the public and private sectors.

To better grasp this debate, we will discuss two distinct issues that have guided our many years of work. These issues could be described as two of the founding elements for urban planning designed to create sustainable, inclusive cities.

The first is urban poverty. Simply knowing that a third of urban dwellers in South countries are poor and live in material and economic precarity on a daily basis very much calls into question the work we do as urban development professionals. We must start thinking of urban planning as a way of fighting poverty.

The second is the focus on small and medium-sized cities, hundreds if not thousands of which (depending on the country) play a decisive role in the exchanges between the countryside and these cities, and serve as regional centers for a multitude of public services. $50 \%$ of the world's urban population lives in cities of 10,000 to 500,000 inhabitants. Often unknown outside of their regions, these intermediate cities face enormous challenges, particularly in South countries where they have the highest population growth rate. Over the next decades, $90 \%$ of the urbanization process will take place in Asia and Africa.

\section{Urban planning in the Global South, occupational hazards}

Many critics have voiced their opinions as to the real impact of planning that does not fully addresses the integration issues faced by a large proportion of the population.

Be it in Koudougou in West Africa, Chau Doc in the Vietnamese Mekong Plain, Montes Claros in Brazil or Nuevo de Julio in the Argentinian pampas - example that we will develop further 
in this text - (Bolay, 2015; Bolay, 2016; Bolay, 2018) the issue of greatest concern to planners is "How can we beautify cities and make them more attractive to city dwellers and investors," not "What can we do to reduce poverty and better integrate poor people living in precarious conditions?"

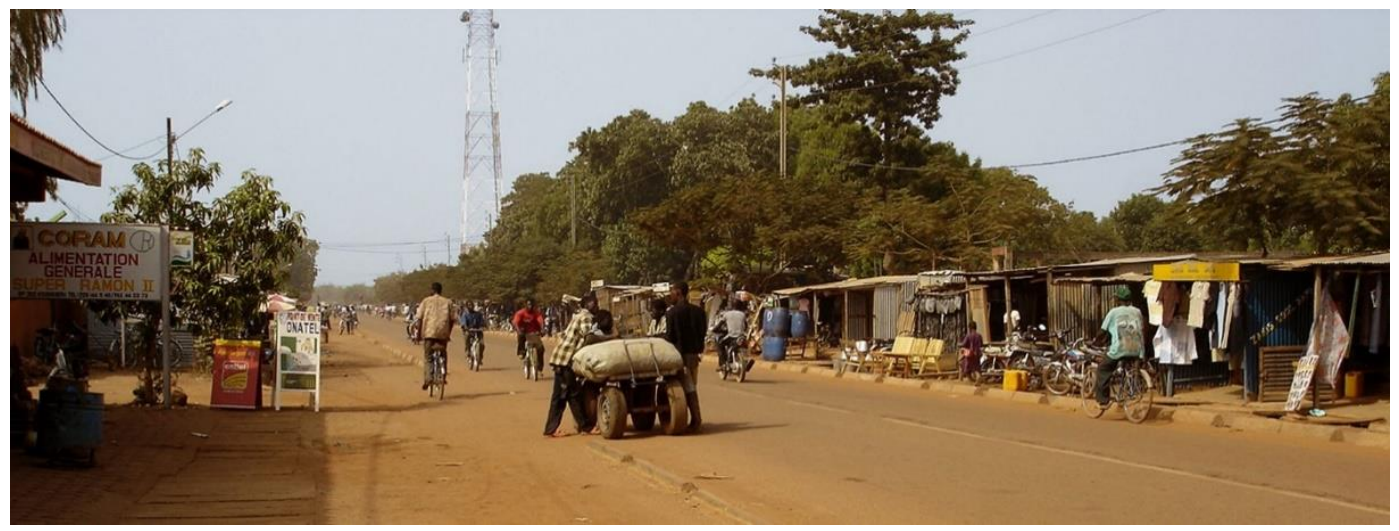

Figure 1 Koudougou, Burkina Faso (Photo by J-C Bolay, 2014)

While not diametrically opposed, the thinking behind these two questions is nonetheless divergent. The former avoids delving too deeply into societal complexity and instead seeks technical solutions to improve the city's functionality (infrastructures, networks, communication routes, equipment, etc.), too often forgetting the universal need for accessibility (i.e. for the poor as well). The second makes citizens the focus by recognizing the fact that integrating people socially, economically and culturally fosters sustainable, inclusive urban development. In this sense, urban planning in South cities is too often incomplete at the spatial level, as experts only focus on specific parts of the territory and typically abandon poor, poorly-regulated and outlying neighborhoods. It is also poorly adapted socioeconomically speaking, as it tends to focus on business districts and the "select" areas that privileged social actors invest in based on their financial status, relationship to power or even community or ethnicity.

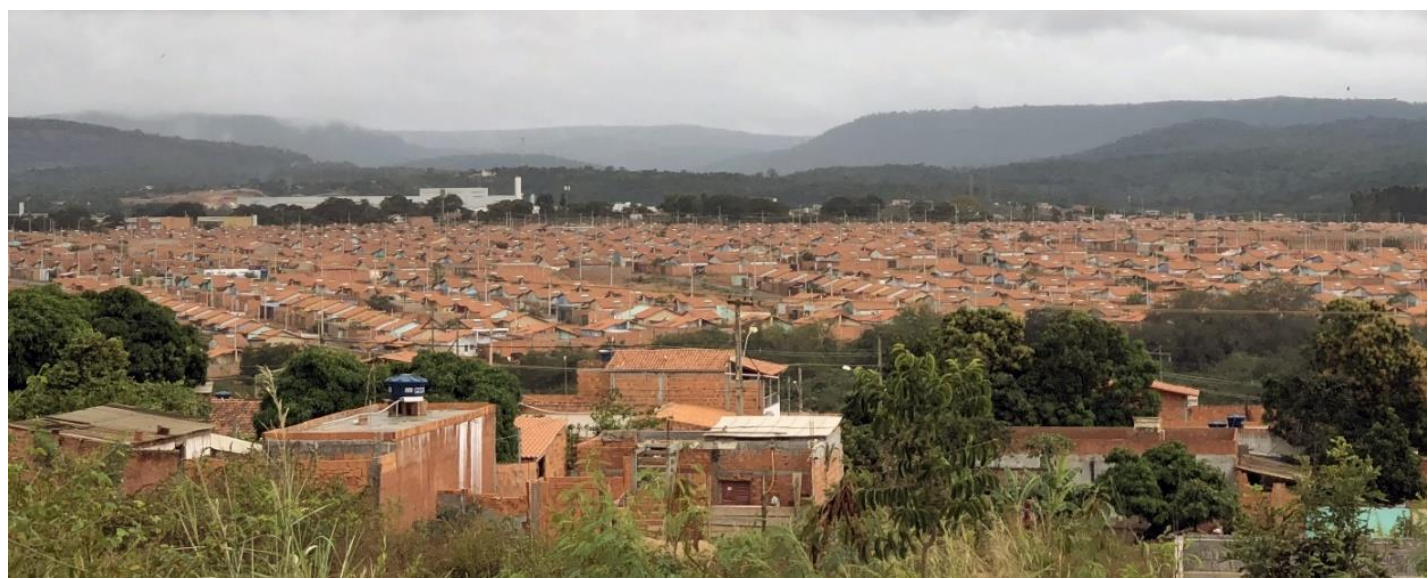

Figure 2 New social settlement in Montes Claros, Brasil (Phot by J-C Bolay, 2018)

Based on a comparative study of nine South cities, Devas (2001) concluded that the standards established for infrastructure, facilities and buildings were completely unsuited to the conditions of the poor, but formed a perfectly workable system of regulation by individuals 
with economic and/or political power. This is largely due to the fact that methodological and technical debates are dominated by Europe and North America, and take Western cities whose characteristics radically differ from those of developing countries - as their point of reference and as experimental sites (Edensor \& Jayne, 2012). Reproducing these recipes in different urban contexts is simply nonsensical and can only offer ineffective solutions. The management of public facilities and services is a good example. Today, the privatization of the latter - which in fact are often no longer public! - is a major trend. Hence the profitability of urban investments and their management takes precedence over their "universality."

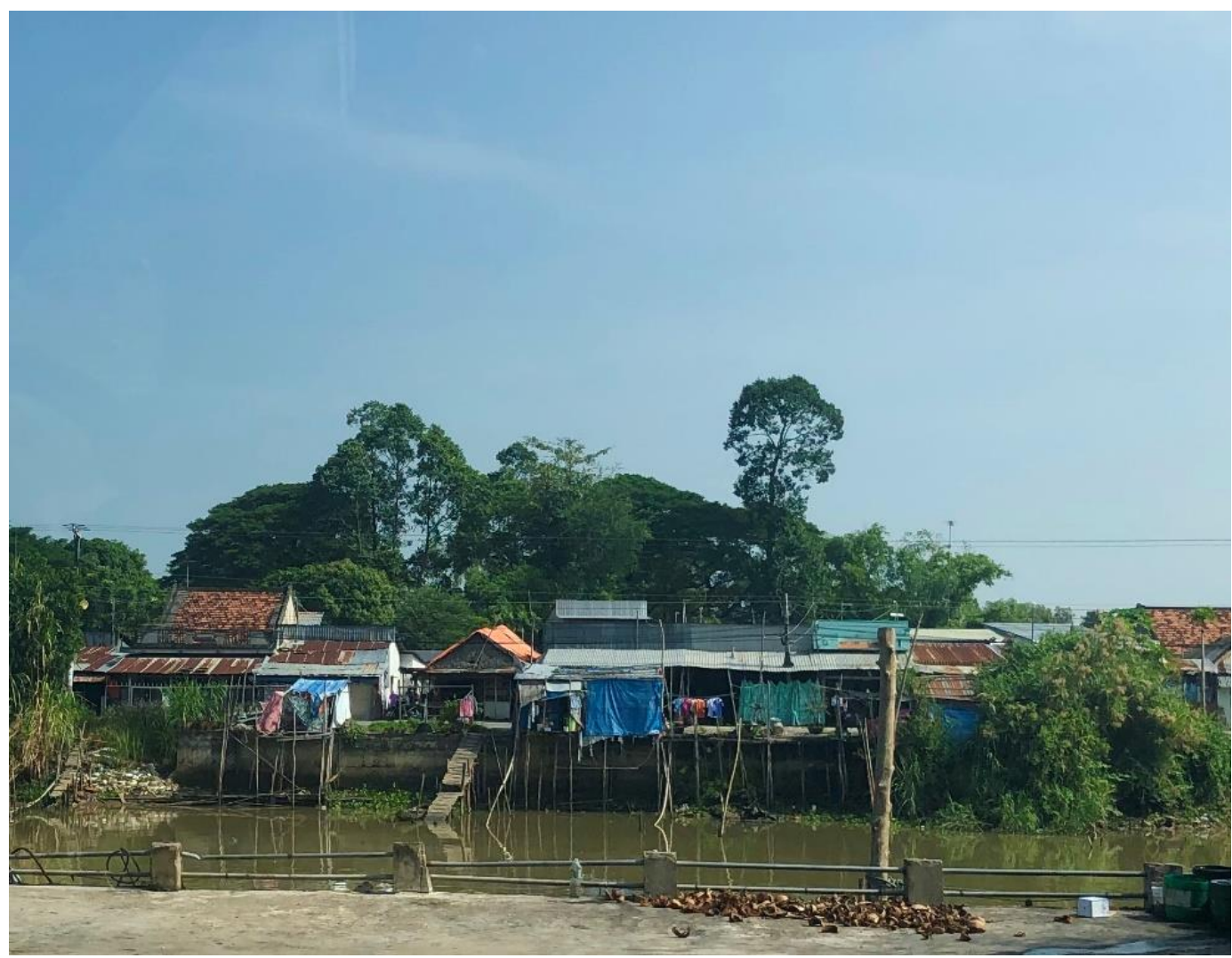

Figure 3 Informal housing along the river in Chau Doc, Vietnam (Photo by J-C Bolay, 2018)

In many South countries and Western countries as well, the management of basic sectors such as water, energy, transportation, culture and public spaces (to name only the most obvious) is now in the hands of private companies. It is perfectly valid and healthy to worry about the balance of public finances. However, it is untenable to do so at the expense of the working classes, whose economic conditions impede their access to a whole range of amenities and services, the charges for which exceed the spending capacity of modest income households. Therefore, the question is who decides on urban investment priorities, based on which criteria, for whose benefit and according to which cost recovery mechanisms (i.e. from users)? For Watson (2009), demographic and territorial growth in South cities inevitably leads to a concentration of poverty and social, economic and spatial inequalities. Urban planning as applied in many developing countries cannot anticipate or solve the multitude of intertwined problems, between the local needs of each family, community and neighborhood, and the production of planning based on the entire urban territory (but with inexplicit priorities) by specialists. 
As the saying goes, "We only lend to the rich." In South cities, the poor know this better than anyone else. Putting aside the social and economic repercussions of urban development, it is normal for companies (public and private) to favor individuals, social groups and, by extension, areas of those city they know will provide a return on their investments. However, they quickly forget that this short-term profitability reinforces social segregation and the fragmenting of the urban territory between rich and poor, and developed and marginalized areas. Though the costs of this are not immediately discernable, they are in the medium and long term. How? Firstly, by creating more and more poor neighborhoods that are in turn neglected by the authorities, with increased insecurity, both real and perceived. Wealthy neighborhoods are equally marginalized and isolated, with gated communities hidden behind walls and protected by private police. The environmental cost is very high, with some parts of the city lacking basic sanitation infrastructure. Natural resources (water, soil and air) are contaminated and impact the health of inhabitants. Again, it is the poor who suffer the most. More indirectly, however, it is society as a whole that pays the price; public schools and public hospitals are reserved for families without sufficient means, savings or social security, while clinics and private schools welcome well-to-do families.

And yet, statistics have long shown that the most dynamic, innovative, richest companies are those that invest in these "social" sectors that benefit all citizens. We must therefore bear in mind the idea of the common good, of going beyond individual dynamics and of rethinking urban planning in a vision of shared urbanity (harmony between the natural/built environment, fighting poverty by favoring social integration, etc.). Though this is feasible and already exists, it is far from being the rule in South cities. Thus, we must reverse the current logic and redefine the priorities of planning.

\section{Planning against poverty, a priority for intermediate cities}

The question of urban development is particularly critical for intermediate cities as well as small and medium-sized cities of 20,000 to 500,000 individuals (Bolay, Kern, 2019), firstly because they are home to roughly $50 \%$ of the world's urban population (United Nations, 2014) and secondly because they are the cities with the greatest urban growth. Despite this, these "ordinary cities" (Robinson, 2006; Parnell \& Robinson, 2012) are generally not on the federal government's radar and receive relatively little federal funding to tackle the urgent issues they face or to invest for the future. Investment priorities are not always based on rigorous diagnostics involving long-term planning processes, but rather are often the result of "opportunities" or pressure from powerful stakeholders (from within the city or outsiders). Inhabitants of these cities suffer the consequences in terms social/material precarity, contamination of natural resources, informality of economic activities, and dysfunctional decision-making and governance. 


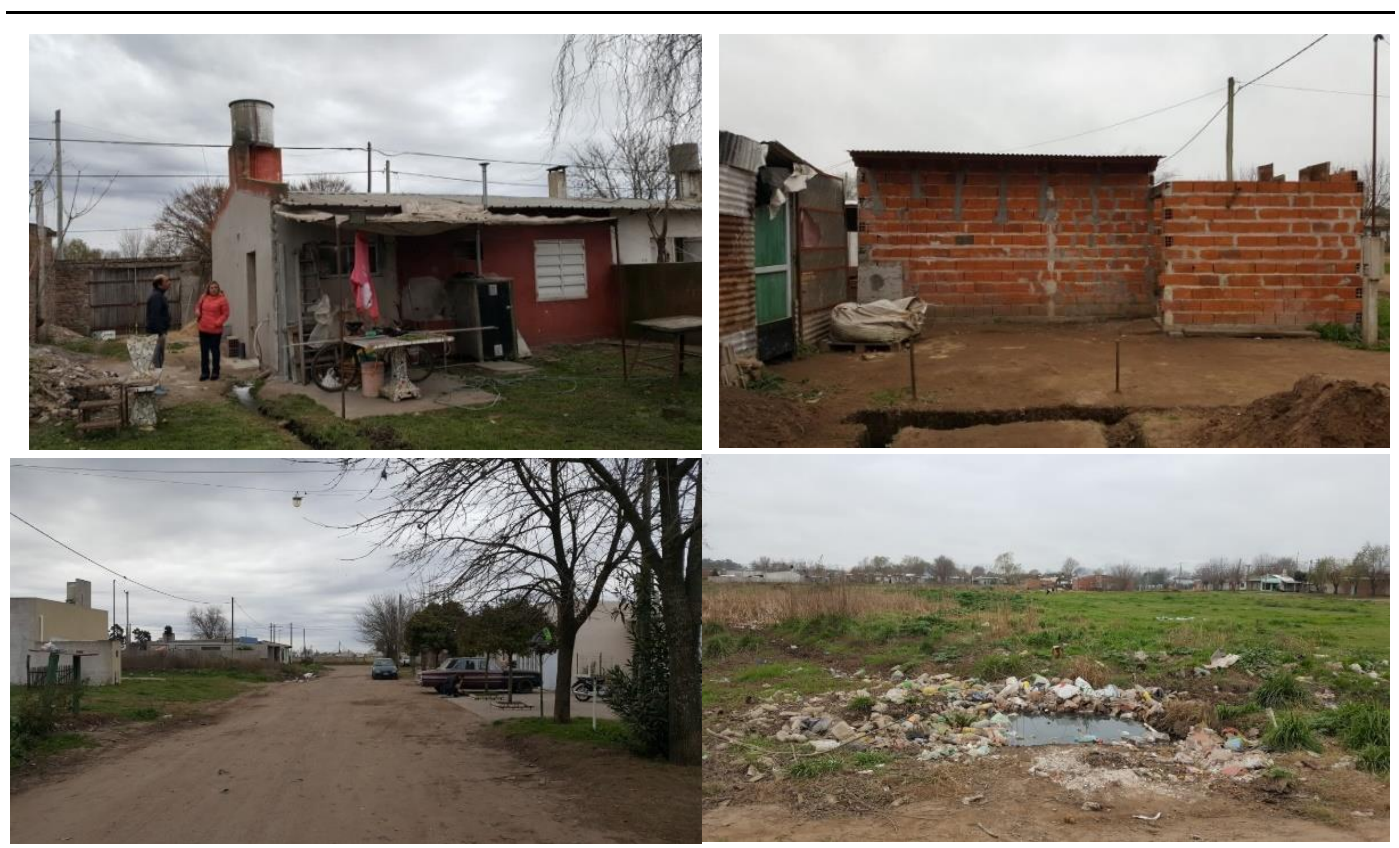

Figures 4-8 “Ciudad Nueva", a poor neighborhood in Nueve de Julio, Argentina (photos by Teo Vexina Wilkinson, CODEV, 2017)

\section{Lessons? Learning from what exists and by doing (better)}

With this urban context of insecurity and uncertainty about the future of these small and medium-sized cities, we can speak of "poor cities," not only because many citizens actually live on the edge of poverty but also because the urban authorities cannot afford the investments needed to improve daily life for residents. Reversing this trend would involve changing urban planning by moving away from development models that were designed to comply with standards and rules in completely different contexts (i.e. Western countries) established by specialists with little to no knowledge of the Global South. The major risk here is projecting onto these cities based on criteria that only serve the interests of a minority - in other words, the wealthy - marginalizing the poor living informally in the most underserved neighborhoods. However, it is also an extraordinary opportunity to think about the future based on what exists, taking into account the actual financial and social resources of these cities, to design and implement urban planning that fights against poverty, and to invest in facilities with a sustainable impact on the poor's living conditions.

Urban planning in developing and emerging countries must be entirely rethought. The essential point, which is too often overlooked, is to start from a participatory diagnosis in which the reality of the city is examined in its various dimensions (demographic, spatial, infrastructural, economic, social and environmental), thus allowing all stakeholders to find their place. This cartographic, documentary and anthropological information should serve as a basis for a database that can then be uploaded with real-time information, thus facilitating the monitoring of "urban development" and a collaborative, up-to-date decision-making process. In parallel remains the question of establishing priorities in terms of lacking 
infrastructure, standards, rules and plans that are tailored to the context, the needs identified by specialists, requests from different social actors, and internal and outside financial resources.

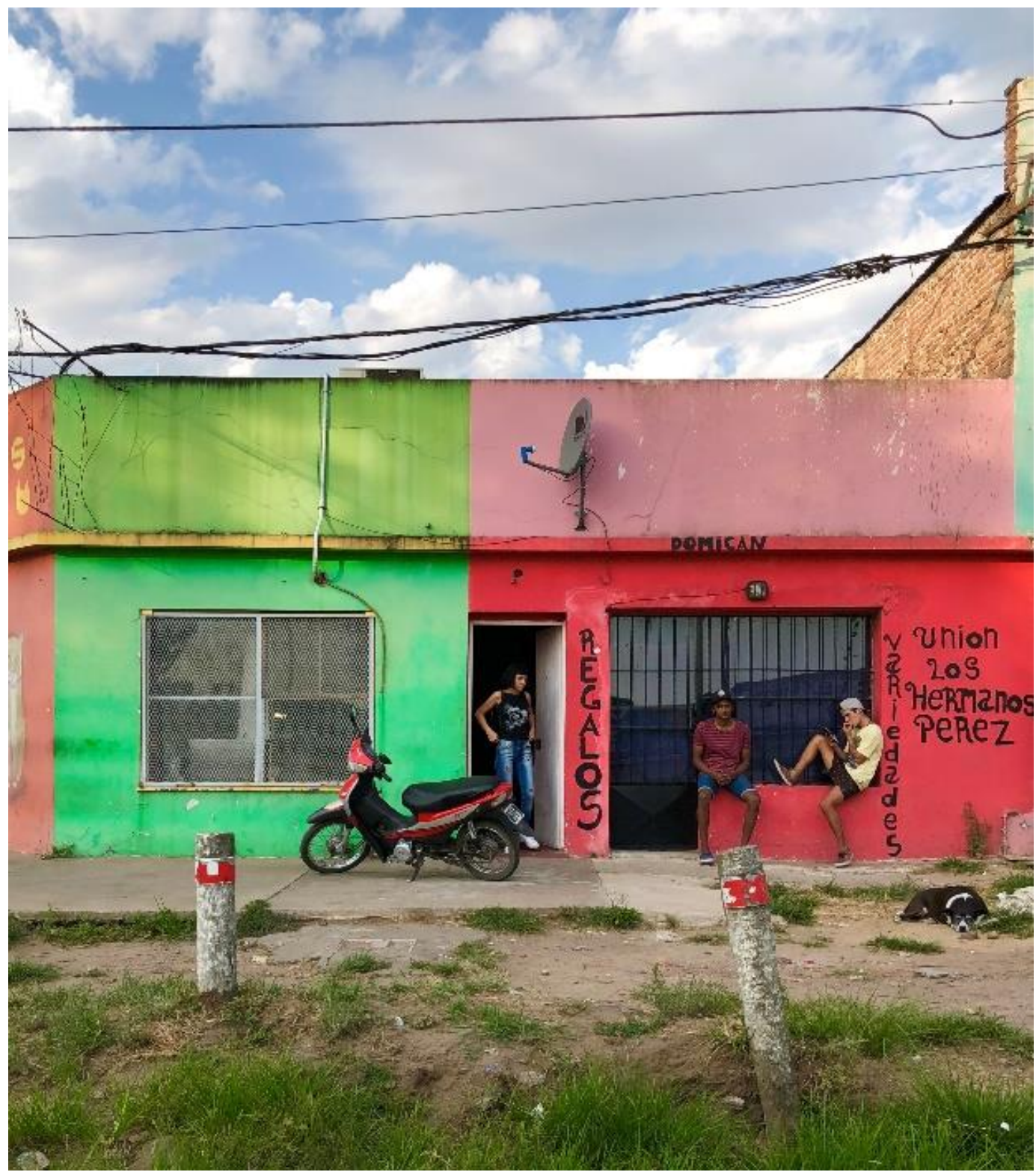

Figure 9 Youth in Nueve de Julio, Argentina (Photo JC Bolay, 2018)

Two principles should guide this process: the first is that urban investments should be used to fight poverty either directly or indirectly; the second is a global vision to guide the specific actions in the short, medium and long terms. These precepts can only be applied if the framework conditions are respected: local and regional governments must have the human competencies and financial resources available that will enable them to take action. This is not impossible if the political will is there and is considered legitimate by the population. This inevitably involves consultation frameworks that will open up a dialogue between representatives of the population, public administration, political powers, industry professionals and other special interest groups (private sector; social, religious, and political groups; NGOs; etc.). 


\section{The city is full of decision makers, so let's train them to be good urban planners}

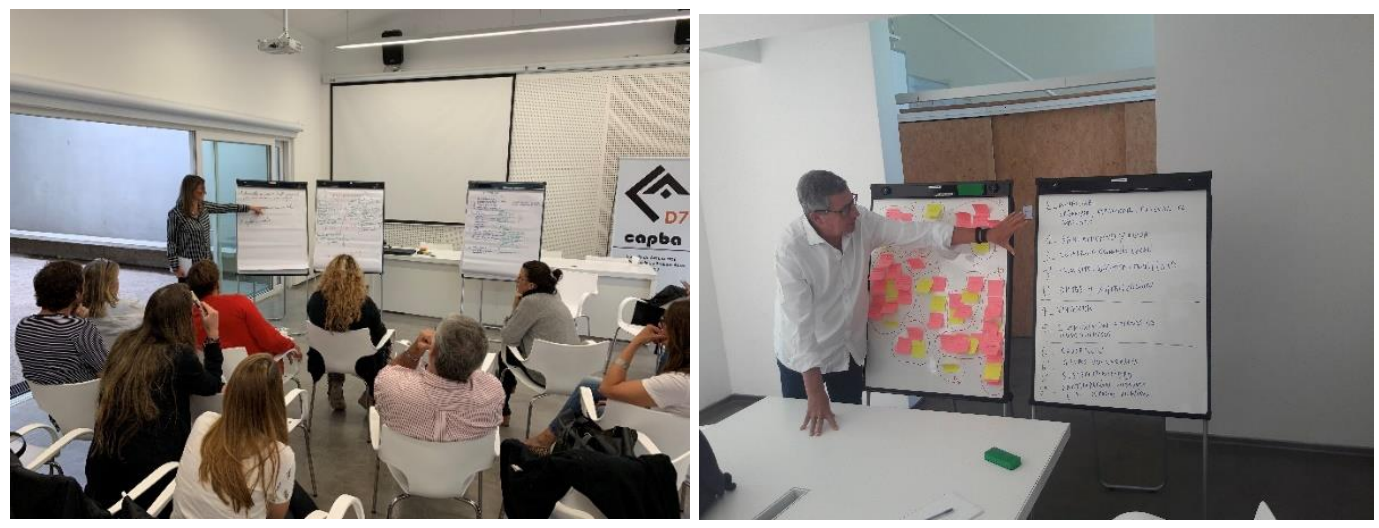

Figures 10-11 Workshop in Pehuajo, Argentina (Photo JC Bolay \& E. Labattut, 2019)

Training plays a key role, as does communication and dialogue. These same guidelines should govern implementation. Here, too, there is room for innovation, starting with social practices and human dynamics outside of the formal context at the local and regional levels. Though the technical know-how of urban and business experts (who too often are absent) is indispensable, inhabitants are nonetheless often forced to take matters into their own hands and wind up doing the job (building homes, community facilities, better managing their neighborhoods, etc.) themselves.

These vital forces should be neither overlooked nor set aside, for they are the very heart and soul of a participatory process that includes not only consultation, but conception and action as well. Rather, these forces can be incorporated into the planning process, where they can be useful in the implementation of collective decisions. Communication is also a key issue. How to learn from other cities via the Internet and increasingly frequent global exchanges on urban matters? As Campbell (2012) explains, we learn from both near and far, and no longer unilaterally from North to South but also from South to South and South to North.

\section{From research to implementation: A collaboration with a network of Argentinian medium-sized cities}

With this urban context of insecurity and uncertainty about the future of these small and medium-sized cities, we can speak of "poor cities,"

The best example of such an approach is what we currently share with the "Colegio de Arquitectos'" in District 7 of the province of Buenos Aires in Argentina, where we have created an urban planning training program for professionals in 15 intermediate cities in the northern part of the province.

This program is in line with SDGs (sustainable development goals) and their role in the urban context, as defined by Objective 11 "Sustainable cities and communities"ii. 


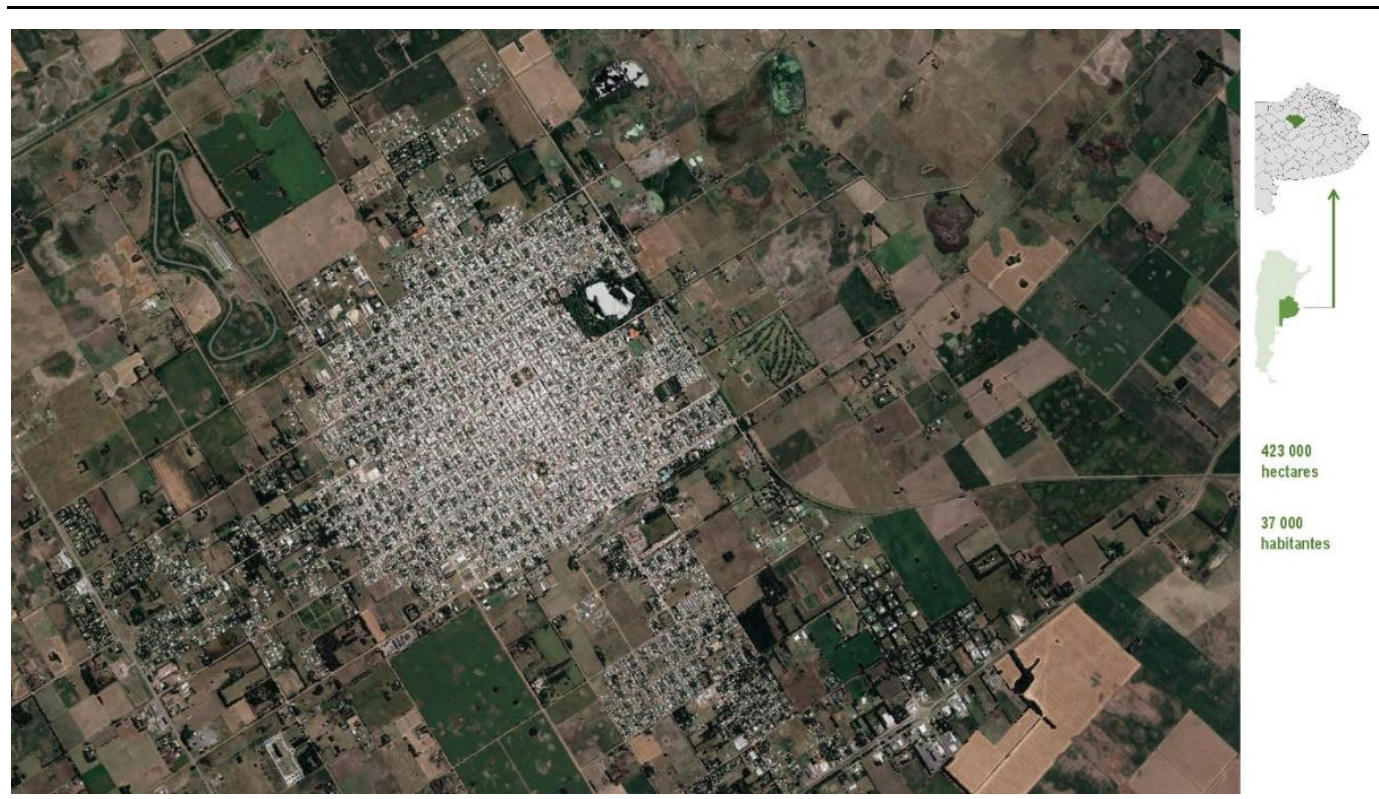

Figure 12 Localization of Nueve de Julio, Buenos Aires Province, Argentina (Google map, 2019)

The project was based on an initial collaborative project between the Municipality of Nueve de Julio - a city of 37,000 inhabitants located $260 \mathrm{~km}$ from the capital, Buenos Aires - and the CODEV. The collaboration helped us to better identify training needs and to determine the appropriate methods. The first project phase was based on the assumption that the urban planning tools available to the municipality were not adapted to the urban and social needs/reality. Effectively, the city's planning department possesses little data on the city. Moreover, it does not even have an updated plan of the networks or a mapping department; in fact, in 2018, it had a single urban planning unit with only two architects. The reference document is a zoning plan, which is a non-versatile urban planning tool that does not convey a project or a vision of the city's development.

Based on these observations, a collaboration agreement was established between the city of Nueve de Julio and the CODEV (Center for Cooperation and Development, Ecole Polytechnique Fédérale de Lausanne, Switzerland), with the central question: how to create a GIS (Geographic Information System) tool with limited resources? Both agreed that the priority was for the municipality to ensure the production and management of data in order to gain a better understanding of the territory while creating a common tool that would facilitate work between the various municipal services. Among the main findings were:

- A lack of human and material resources for urban planning at the municipal level;

- The lack of a unifying project for the city in terms of urban and territorial planning beyond the urban code (zoning plan);

- Incomplete urban data scattered among the various municipal services;

- A need to include more urban actors, namely residents but also service providers such as the service cooperative, the university sector, etc. 
The municipality of Nueve de Julio agreed on the priorities of developing human resources and investing in material and technological resources. In turn, the CODEV agreed to support its effort on planning data acquisition. To do so, a list of 35 essential GIS layers was developed along with an inventory of the availability of this basic data within the municipality (Cortat, 2017). These 35 layers were ranked in order of priority from 1 to 3 depending on their importance ( 1 being of the highest importance, 2 of medium importance and 3 of minor importance). A synthesis of this work showed that a certain amount of data already existed, even if it sometimes appeared in an inappropriate file format, was not digitized or had not been updated. The conclusion was that half of the basic data existed and the other half needed to be collected.

Three priority actions were then proposed to the municipal planning department: (1) to start building an initial database with existing data after digitizing and converting it to the appropriate formats; (2) to prioritize by assessing the benefits and viability of each production or acquisition of an additional dataset; and (3) to work in collaboration with other actors in order to obtain as much data as possible. It quickly became clear that setting up data collection, even minimal, would prove difficult for the municipality's urban planning department, which has neither the staff, nor the equipment, nor even strong political support from the mayor. To circumvent these issues, the partners envisaged refocusing the project on the Ciudad Nueva neighborhood - an area of 10,000 inhabitants living in precarious living - by developing a participatory citizen mapping process to demonstrate that a lack of financial and human resources could be overcome using simple, inexpensive technologies. But by late 2018 , the proposal had run up against political blockage and the project ended in a stalemate.
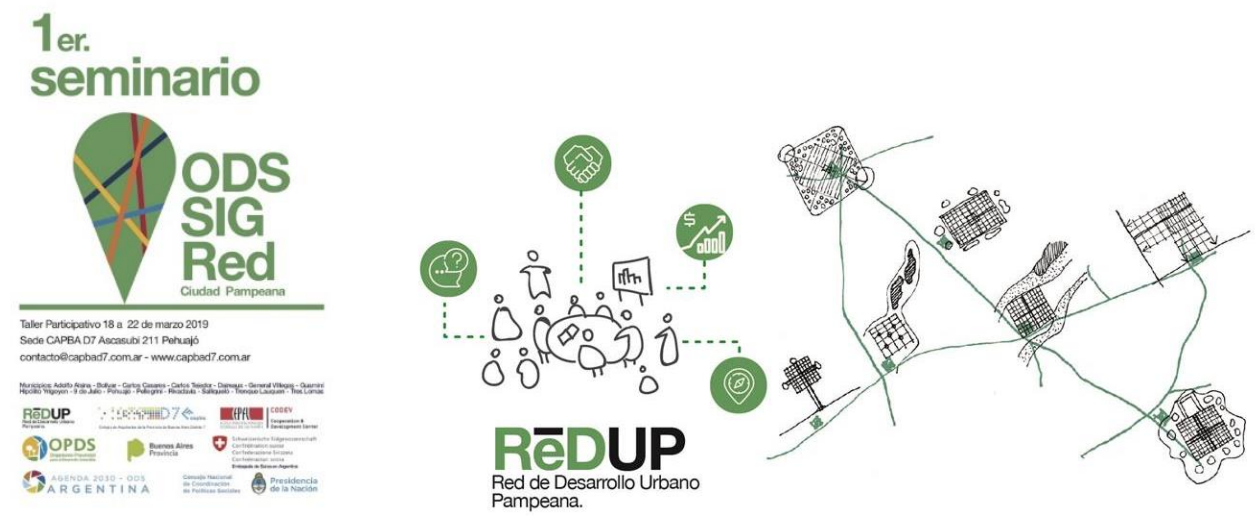

Figures 13-14 Information on the first training workshop in Argentina (CAPBA, 2019)

The second phase aimed to work with a network of cities in the Northern part of the province of Buenos Aires to overcome such local political blockages. In early 2019, the CODEV launched this phase along with the "Colegio de Arquitectos (CAPBA)," an important and recognized institution in Argentina that is present throughout the country thanks to regional and district representation. The Colegio de Arquitectos of District 7 (CAPBA D7) is setting up a network of cities, the "Red de Desarrollo Urbano Pampeano (ReDUP)," which comprised 15 cities of less than 50,000 inhabitants and includes Nueve de Julio. A first seminar helped highlight the fact that the problems in Nueve de Julio (unplanned urban development, lack of data, inappropriate planning tools, etc.) were in fact common to all the cities in the network. The CAPBA D7 and the CODEV thus established a research agreement in December 2018 to work at this new scale so as to overcome political blockages at the local level and provide support 
to municipal staff in high demand. The project is in line with the network's general objectives of promoting knowledge sharing and experimentation at the regional level, pooling resources and developing appropriate tools and training for municipal technicians.

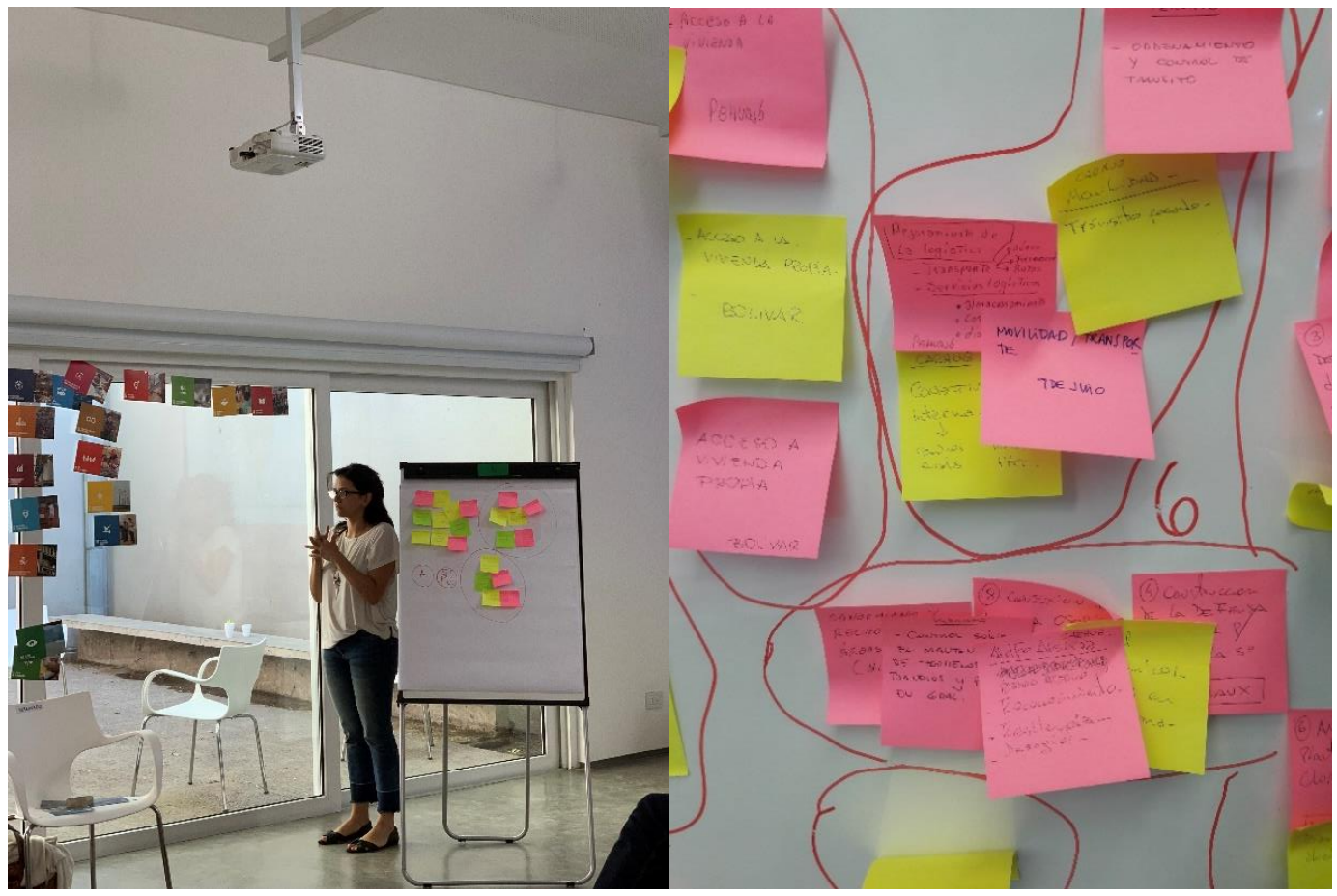

Figure 15 Workshop in Pehuajo, Argentina (Photo JC Bolay \& E. Labattut, 2019

This new project phase, which ends in December 2019, will allow for a regional diagnosis of the priorities of each city and the network as a whole in terms of urban planning and the need for GIS tools development.

The working seminars with municipal technicians, the first one organized in March 2019 in Pehuajo and the second one planned for September 2019, will be used to draw up specifications for the construction of a GIS platform that is adapted to the needs of the network as well as for the implementation of a training program, supported by the Colegio and by provincial and national institutional partners who have since joined the initiative.

\section{Conclusion: Between crises and urban strategy, the challenges of planning}

Our conceptual thinking on the need to quickly find innovative ways to design and develop urban planning in South cities is reinforced by our fieldwork experience as well as the local and regional collaborations that have been set up.

Today we are at a turning point. Having spent a considerable amount of time studying its practical application in African, Latin American and Asian cities that are extremely divergent, 
we have now moved into this new training and local capacity-building phase for urban and regional planning.

At the end of a first seminar that brought together municipal technicians from nearly 15 intermediate cities in the province of Buenos Aires, Argentina, some useful lessons were learned for the remainder of the process.

First, in order to define priorities for each city, a shared diagnosis must be established as a first step. This should not only be based on analyses by urban experts - municipal technicians and professionals - but should also include other stakeholder groups. To implement it, cities must have data and analyses at their disposal to observe the major phenomena and dynamics at work in their territory, at the environmental, economic, social and urban levels. But analyzing territories based on data would require a significant change in the municipal work culture, including new skills for technicians, integrating new tools and developing new approaches to interdisciplinary collaboration.

Secondly, for most of these technical experts, planning is first and foremost a task to be managed between planners, engineers and computer scientists. Other communal or regional services - social, health, environmental or cultural - are there to provide data that the former can then process and analyze. Municipal technicians' request is therefore primarily technocratic: to provide them with databases and computer platforms that they can then share, geotag and analyze. This hierarchy of responsibilities and tasks implicitly extends to other urban actors (inhabitants, lobby groups, social or economic groups). At this stage, however, citizen participation is still an abstraction. We still have a lot of work to do together to prove that this dialogue between all of the interested parties is not intended to minimize the work of technicians or their skills, but rather to enrich the database based on social demands. Above all, it should serve to boost urban management by taking collective responsibility for this "common good," this shared urbanity and living environment that is supported and respected by all.

Urban planning is not an end in itself: it is a human and technological way to anticipate the future and act in a coherent, responsible way to guarantee urban and peri-urban residents' well-being. To address the real problems that urban inhabitants and authorities face, planning must create collective infrastructures and access to services that aim to reduce poverty and develop a more inclusive city with better organization, in order for it to be environmentally, socially and economically sustainable.

The field work carried out during recent years in small and medium-sized cities in Burkina Faso, Brazil and Argentina is helping us to attract the attention of specialists and decision makers to intermediate cities that, though they are home to half of the world's urban population, are little studied. All of these small and medium-sized cities face various forms of precarity, with relatively large poor populations, local governments that lack both the financial means to invest in solving the problems they face and the human resources to initiate and manage an efficient planning process. In most of these cities, the governments are still not open to democratic participation processes and do little to incorporate social demands into their development plans.

Based on this analysis, we consider it is imperative to reinvent urban planning as part of a more participatory process that meets the expectations of citizens with more realistic criteria. 
This process involves different phases: an analysis phase grounded in the identification of urban investments needed to improve the city; consideration of social demands; a realistic assessment of the financial resources available (municipal budgets, taxes, public/international grants, public-private partnerships), and; a continuous dialogue between urban actors to determine the urban priorities for the coming years.

This protocol shall serve as a basis for the training program initiated in Argentina for urban actors in small and medium-sized cities, which we hope to later extend to other the South countries.

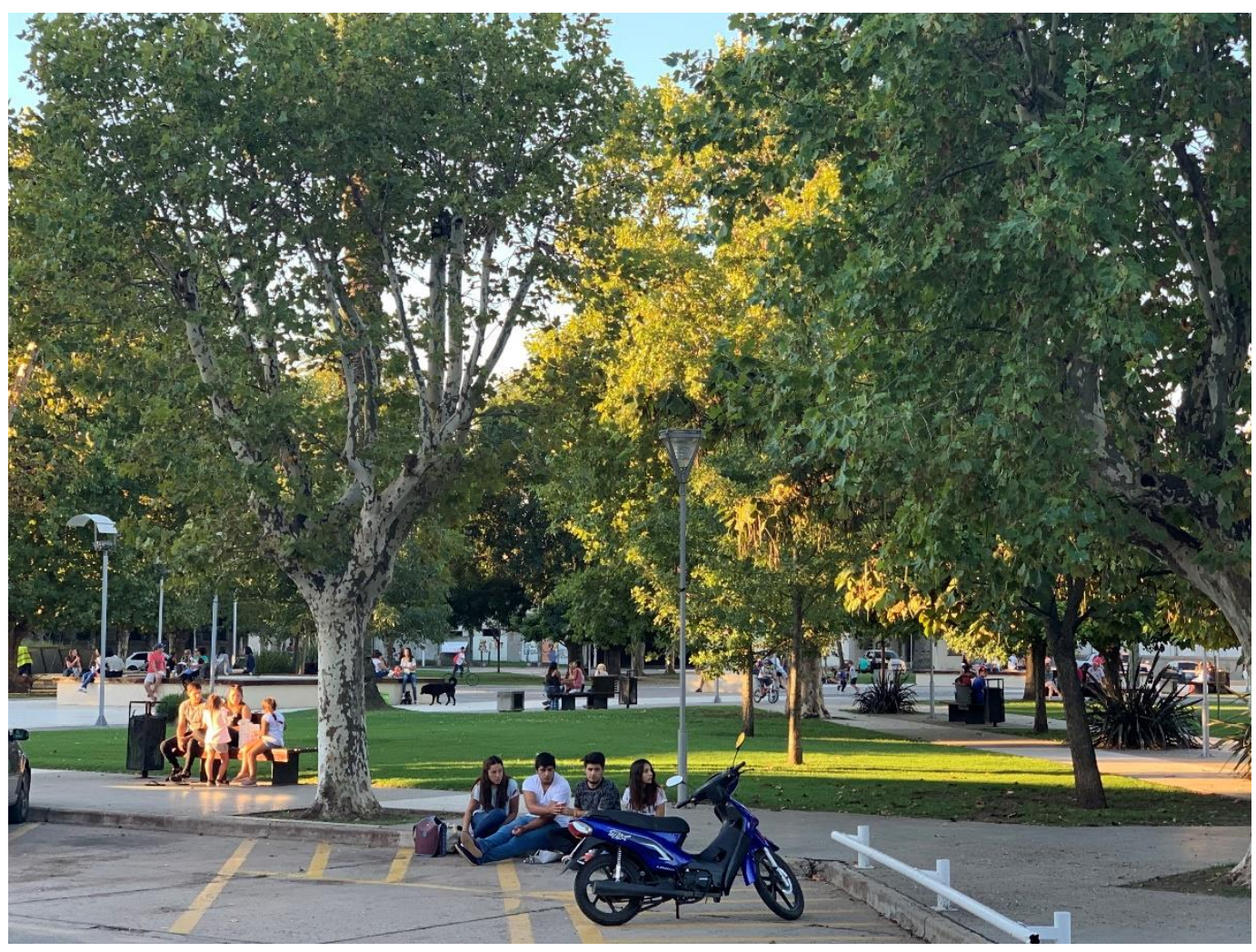

Figure 16 The central place of Pehuajo, Argentina (Photo JC Bolay, 2019)

\section{References}

Bolay, Jean-Claude; Kern, Abigail Laure (2019) "Intermediate Cities", Wiley-Blackwell Encyclopedia of Urban and Regional Studies. Hoboten, Wiley-Blackwell.

Bolay, Jean-Claude (2018) "Planning the Intermediate City, or How to Do Better with Little: The Case of the City of Nueve de Julio, Argentina", Current Urban Studies, Vol. 06 No 03, pp.366-400, DOI: 10.4236/cus.2018.63020

Bolay, Jean-Claude (2016) "Prosperity and Social Inequalities: Montes Claros, How to Plan an Intermediary City in Brazil”, Current Urban Studies, Vol 04 No 02, pp. 175-194, http://dx.doi.org/10.4236/cus.2016.42013. 
Bolay, Jean-Claude (2015) "Urban Planning in Africa: Which Alternative for Poor Cities? The case of Koudougou in Burkina Faso", Current Urban Studies, Vol. 3, No. 4, pp. 413431, DOI:10.4236/cus.2015.34033.

Campbell, Tim (2012) Beyond smart cities. How cities network, learn, and innovate, London, New York, Earthscan.

Cortat, Jasmine (2018) Stratégie d'implantation d'un outil SIG pour de petites villes dans les pays du Sud. Etude de faisabilité : 9 de Julio, Argentine, Lausanne, CODEV EPFL.

Devas, Nick. (2001) "Does city governance matter for the urban poor?", International Planning Studies, Vol. 06 No 04, pp. 393-408, https://doi.org/10.1080/13563470120092395

Endensor, Tim; Jayne, Mark (2012) Urban Theory Beyond the West. A World of Cities, London, New York, Routledge.

Parnell, Susan; Robinson, Jennifer (2012) "(Re)theorising cities from the global south: looking beyond neoliberalism", Urban Geography, Vol. 33 No 04, pp. 593-617.

Robinson, Jennifer (2006) Ordinary Cities: Between Modernity and Development, London, Routledge.

United Nations, Department of Economic and Social Affairs, Population Division (2014) World Urbanization Prospects: The 2014 Revision, Highlights, New York, United Nations. https://esa.un.org/unpd/wup/publications/files/wup2014-highlights.Pdf.

Watson, Vanessa (2009) "Seeing from the South: Refocusing Urban Planning on the Globe's Central Issues", Urban Studies, Vol. 46, pp. 2259-2275.

Colegio de Arquitectos de la Provincia de Buenos Aires, distrito 7: ReDUP (Red de Desarrollo Urbano Pampanea) http://www.capbad7.com.ar/default.aspx

ii https://www.undp.org/content/undp/en/home/sustainable-development-goals/goal-11sustainable-cities-and-communities.html 